\title{
Reborn the Controversy Related with the use of Sulfonylureas
}

\author{
Arturo Zárate* and Renata Saucedo \\ Department of endocrine Research Unit, National Medical Center, Instituto Mexicano del Seguro Social, National University \\ of Mexico, México
}

Received: May 10, 2014; Accepted: May 10, 2014; Published: May 16,2014

*Corresponding author: Arturo Zárate, University of Mexico, Cuauhtemoc 330, Mexico DF 06720, Tel: 5255 55887521, E-mail: zaratre@att.net.mx

It is generally believed that the initial management of people with type 2 diabetes is based in the acceptance of a change in the life style which includes avoid overweight and regular physical activity. When is necessary to add a pharmaceutical drug to reduce hyperglycemia it is important to bear in mind that antidiabetic agents act through different mechanisms of action, including reduction in hepatic glucose production, stimulation of insulin secretion and increasing insulin sensitivity in peripheral tissues [1,2].

Metformin is recommended as initial therapy, since does not provoke hypoglycemia and weigh gain, nor is associated with important side effects; in addition is one of the least expensive diabetes drugs. Nevertheless nearly half of patients, who initially achieve glycemic control within accepted normal limits, show a progressive deterioration of glucose control after two or three years. At the present, sulfonylureas are generally combined with metformin in basis of their effectiveness and low cost [3,4]. At the 1970 decade was published the study named University Group Diabetes Study Program which showed that glycemic management using sulfonylureas was associated with an unexpected risk of higher mortality due to cardiovascular events. This finding was followed for a great controversy and a deep discussion; resulting in the recommendation of caution for the use of sulfonylureas for the treatment of diabetes [5].

It is important to emphasize that most patients with type 2 diabetes will have to eventually use more than one drug to achieve glycemic control. The new drugs are more expensive (insulin, thiazolidinediones, meglitinides, glucagon-like peptide-1 agonist, and dipeptidyl peptidase-4 inhibitors) and enough time has not passed to assess their safety [4].

Compared with newer agents, older agents have similar or superior effects on glycemic control and cardiovascular risk factors (blood pressure, lipid levels, and body weight). Some of the newer diabetes drugs have been associated with heart failure [6-9]; moreover, a recent report from the Clinical Practice Research Datalink in United Kingdom which was presented at the annual meeting of the European Association for the study of Diabetes in 2013, analyzed patients with type 2 diabetes using metformin or sulfonylurea as monotherapy in the interval 2000 and 2012 and showed that overall mortality was significantly increased in patients receiving sulfonylurea as compared with those using only metformin. Patients under sulfonylurea as monotherapy were 58 percent more likely to die from any cause than those taking metformin [10]. Therefore, these data have to be taken into account for the selection of the initial therapy, mainly for economic reasons of public health services.

Ideally the therapeutic decision should be based on long-term effectiveness. There is general agreement on the first-line use of metformin in most patients with type 2 diabetes; however, there is no enough evidence for the selection of the most appropriate medication as the second-line agents.

\section{References}

1. Lebovitz HE (1988) Keeping tabs on oral agents. Diabetes Care 11(7): 598599.

2. Zarate A, Basurto L, Saucedo R, Hernandez-Valencia M (2010) Guia para seleccionar el tratamiento farmacologico en diabetes 2. Rev Med Inst Mex Seguro Soc 48(3): 293-296.

3. Ismail-Beigi F (2012) Glycemic management of type 2 diabetes mellitus. N Engl J Med 366: 1319-1327.

4. Zarate A, Islas S, Saucedo R (2014) Eficacia y efectos adversos de los antidiab eticos orales. Gaceta Médica de México 150: 5-7.

5. Leibel B (1971) An analysis of the University Group Diabetes Study Program: data results and conslusions. Can Med Assoc J 105(3): 292-294.

6. Hemmingsen B, Lund SS, Wetterslev J, Vaag A (2009) Oral hypoglycaemic agents, insulin resistance and cardiovascular disease in patients with type 2 diabetes. Eur J Endocrinol 161(1): 1-9.

7. Gerstein HC, Miller ME, Genuth S, Ismail-Beigi F, Buse JB, et al. (2011) Long-term effects of intensive glucose lowering on cardiovascular outcomes. N Engl J Med 364(9): 818-828.

8. Nissen SE, Wolski K (2007) Effect of rosiglitazone on the risk of myocardial infarction and death from cardiovascular causes. N Engl J Med 356(24): 2457-2471.

9. Home PD, Pocock SJ, Beck-Nielsen H, Curtis PS, Gomis R, et al. (2009) Rosiglitazone evaluated for cardiovascular outcomes in oral agent combination therapy for type 2 diabetes (RECORD): a multicentre, randomized, open-label trial. Lancet 373(9681): 2125-2135.

10. Morgan CL, Mukherjee J, Jenkins-Jones S, Holden SE, Currie CJ (2014) Association between first-line monotherapy with sulfonylurea versus metformin and risk of all-cause mortality and cardiovascular events: a retrospective, observational study. Diabetes Obes Metab. 